\title{
Study on flexible structure with waterproof, breathable and thermal insulation in concrete construction
}

\author{
Junyou Zhou ${ }^{1}$, Peiyin Wen ${ }^{1}, \mathrm{Hu} \mathrm{Li}^{1}$, Yongjie $\mathrm{Lu}^{1}$ \\ ${ }^{1}$ The College of Environment and Civil Engineering
}

\begin{abstract}
Absrtact. with the development scale of urbanization construction in China, the technical standard of concrete construction is getting higher and higher. It is the key breakthrough direction of technology to strengthen waterproof and air permeability in concrete construction.Nonwoven formwork lining technology is a way to improve the impermeability of concrete structure surface to achieve the overall durability of concrete structure. Some hydrated residual water and large bubbles of concrete at a certain depth of surface layer are discharged, thus reducing the water-cement ratio of concrete, realizing the compactness of structural surface, increasing the strength and hardness of concrete surface, and achieving the purpose of improving the performance of surface concrete. This paper mainly analyzes the flexible structure of waterproof, breathable and heat preservation, and puts forward personal views and viewpoints.
\end{abstract}

\section{Background and significance of the study}

Portland cement was invented by British Asputin in 1824 . Because the color of this solidified and hardened cement is the same as that of the stone in Portland, England, it is named Portland cement. Portland cement grinds the stone into sand, then binds the stone and sand together, and modern concrete is born. Houses built of all concrete structures also appeared in Britain in 1835. By 1875, William Russell (William Brussels) had patented reinforced concrete, which was invented to build low-rise houses with reinforced concrete preforms. The French Eu gen and Freshness invented prestressed reinforced concrete in 1917 and developed a prestressed concrete structure.

The emergence of modern concrete (or reinforced concrete) is a major progress of human civilization, which has completely changed the materials and characteristics of building structures. With its obvious advantages of easy casting, economy, energy saving and high rigidity, modern concrete has become the most widely used building material in the world and has become an indispensable material in social and economic life.

Concrete (or reinforced concrete) structures have also exposed many problems in their applications: their mechanical properties, such as bending resistance (bending), mechanical properties, such as wear resistance and durability, are increasingly unable to meet the needs of the real society, especially structural durability problems.

The durability of concrete structure refers to the characteristics of maintaining its working ability under the action of natural environment, use environment and internal factors, that is, the ability of concrete structure to resist external environment and internal erosion and damage in design service. Data at home and abroad show that durability failure of concrete is one of the most important reasons for structural failure. The resulting damage directly affects the normal use of the structure and seriously threatens the safety performance of the structure.

Under the influence of use and natural environment, the service life of concrete structure often can not meet the design requirements under the current construction method. The social, environmental and economic losses caused by insufficient durability of concrete structures far exceed people's estimates. Taking the average life span of newly built buildings in China less than 30 years as an example, the annual economic losses are hundreds of billions of yuan, and the construction waste is 100 billion tons. For 30 years, this will be intolerable for a country with extremely limited resources and financial resources, on average by population. Therefore, academician $\mathrm{Wu}$ Zhongwei, a famous concrete material expert, listed durability as the first of several key issues in the development of concrete technology in China at the beginning of the 21 st century, and said it was the most important issue of sustainable development.

Because of the lack of durability of concrete structure, it has caused great losses to many countries in the world, including China. Therefore, in order to improve the durability of concrete structures, scientists and technicians from all over the world have carried out a lot of research and exploration in the aspects of concrete composition materials, admixture use, physical and chemical protection of structures and building control.

By means of a flexible structure of waterproof, breathable — permeable formwork lining, the gas and

jyzhou9@163.com 
excess moisture in the concrete surface layer are removed and the loss of cement particles is blocked through the special physical structure. The cement particles are enriched in the surface layer of the structure, which improves the strength of the concrete surface and reduces the permeability of the surface layer. By improving the durability and appearance quality of concrete structure, the huge maintenance cost will be reduced in the future.

\section{Status and problems of technological development}

\subsection{Status of technology}

the current research in our country, flexible structural materials are mainly used to improve the surface quality of concrete by such methods as cement mortar wipe surface + plastic film laying method, cement mortar wipe surface or wood formwork + thin plate sticking method, cement mortar wipe surface + floor leather laying method, steel mould + spraying method, steel mould sticking PVC plate method and steel mould + painting method.

The second and third phases of the Shenzhen Yankou Port Area project, which was invested by Hong Kong and Huang Group, opened the way for permeable formwork in mainland China. After using the permeable formwork, the surface of concrete members is smooth, dense and uniform, and the tone is consistent. There are no defects such as sand lines, sand spots, honeycomb holes, atmospheric holes and so on. In the acceptance of berths 6 and 7, the appearance of the wharf obtained a high score of more than 95 points, and the qualified rate of durability testing of site structure sampling was 100. In recent years, in other coastal bridges such as Hangzhou Bay Bridge, Donghai Bridge and Runyang Bridge and some military projects, the construction of permeable formwork is adopted, but mainly foreign products, there are no professional manufacturers in China.

The research of this aspect in our country lags behind, Tsinghua University is the earliest unit engaged in the research of permeable template in mainland China. In the laboratory, they studied the early permeable templates, which were composed of common templates drilled on the surface and composed of gauze and coarse cloth permeable layer. The test shows that in the depth and 100 $\mathrm{mm}$ range, a certain distance from the top surface is effective. The water cement ratio decreases, the surface hardness increases by 20-35, the compressive strength increases by $10-25$, and the wear resistance increases by 25, which improves the frost resistance and impermeability. Subsequently, many domestic research institutions and institutions of higher learning carried out the application of permeable template experimental research, and achieved a lot of results.

Japan studied and developed permeable formwork 10 years ago to improve the durability of concrete structures. However, due to cost and other reasons, there is in fact no implementation and no funding. A new assessment of permeability templates has been carried out in recent years, especially in Western Europe, referred to as $\mathrm{CPF}$ (permeability templates).
American Building Materials Technology Association also has some research breakthrough, permeable template (CPF) must first be covered by permeable film, which has the function of transporting and releasing residual water and air. Permeable membranes are usually chemical fiber products, such as polypropylene, but there are examples of natural fiber products.

Australia has predicted the cost of using permeable formwork for the peripheral use of reinforced concrete buildings. In the prediction, it is assumed that the durability of the building depends on the strength of the concrete, and the concrete with permeable formwork can significantly improve the strength of the concrete, so the design strength of the concrete can be reduced in the design.

\subsection{Problems}

The research and application history of CPF concrete is very short (not long) compared with ordinary concrete. In the theory of structural durability design and concrete construction measures of CPF concrete, there is a lack of guiding theoretical basis.

For the main factors affecting the durability of concrete structures (such as carbonization, corrosion of steel bars, freeze-thaw failure, chloride salt and sulfate corrosion, alkali aggregate reaction, etc.), many theoretical results have been formed in the practice of ordinary concrete, but the research results in CPF concrete are relatively lacking.

In the process of improving ordinary concrete construction, a suitable construction method has been formed. However, in the process of CPF concrete construction, especially in view of the present situation of our country, the concrete construction measures are far from meeting the construction requirements

The period of rapid economic development in developed countries has been completed, and under the condition of high durability requirements, these countries have the ability to replace concrete structures such as steel structures. Our country is a country with extremely scarce resources and financial resources (on average by population) and is now in a period of rapid economic development, which will last for decades. How to improve the service life of building structures is an important issue that we will have to face before us.

Study on the key technology of waterproof, breathable and thermal insulation flexible structure

\section{Results}

\subsection{Nonwoven template lining technology}

According to the research results of material composition and durability of concrete, the formation of permeable channel of concrete surface is closely related to watercement ratio.The numerical calculation formula of prestress load is as follows:

$$
P_{0}=P_{\mathrm{c}}-Y_{\mathrm{h}}
$$

The total value of $\mathrm{P} 0$ prestress is $\mathrm{Pc}$ the total value of 
stress and tension of nonwovens, and the $\mathrm{Yh}$ is the cost of prestress consumed. According to its prestress value and base value, the calculation can be obtained. After the calculation of base prestress, the circumferential stress is calculated. The formula of stress foundation is as follows:

$$
\delta \theta=P D / 2 \mathrm{~s}
$$

(Formula 2)

The circumferential stress produces the stress effect when the surface characteristics of the concrete molding machine solidify. The key stress of the nonwoven formwork lining structure technology lies in the ability to decompose the stress accumulated in the base by the circumferential stress. Thus better support plane and integral structure. In the face of some thin-walled concrete can play a strong and durable moisture-proof support, its calculation formula in the thin-walled improvement formula is:

$$
\delta \theta=P D / 4 \mathrm{~s}
$$

(Formula 3)

According to the numerical calculation of stress structure, the distribution of technical data is shown in Table 1.

Table 1 Statistics on the distribution of stress data in nonwovens

\begin{tabular}{ccc}
\hline Project & $\begin{array}{c}(\mathrm{N} / \mathrm{m}) \text { Original } \\
\left.\text { stress }^{2}\right)\end{array}$ & $\begin{array}{c}(\mathrm{N} / \mathrm{m}) \text { Improved } \\
\left.\text { stress values }^{2}\right)\end{array}$ \\
\hline $\mathrm{P} 0$ & 128.98 & 29.54 \\
$\mathrm{PD} / 2 \mathrm{~S}$ & 234.56 & 311.98 \\
$\mathrm{PD} / 4 \mathrm{~S}$ & 245.65 & 285.45 \\
\hline
\end{tabular}

As shown in Table 1, the improvement value of the base is the largest among the stress data distribution of the nonwoven template lining, and the original stress value is $128.98(\mathrm{~N} / \mathrm{m})$ Annex $\left.^{2}\right)$, the stress value after improvement is $29.54(\mathrm{~N} / \mathrm{m})$; and $\left.\mathrm{a}^{2}\right) ; \mathrm{PD} / 2 \mathrm{~S}$ original stress value is $234.56(\mathrm{~N} / \mathrm{m})$; and $\left.^{2}\right)$, and the stress value after improvement is $\left.311.98(\mathrm{~N} / \mathrm{m}) .1^{2}\right)$; $\mathrm{PD} / 4 \mathrm{~S}$ original stress value is $245.65(\mathrm{~N} / \mathrm{m})$; and $\left.{ }^{2}\right)$, the stress value after improvement is $285.45(\mathrm{~N} / \mathrm{m})$; and $\left.^{2}\right)$. Through numerical analysis, it can be seen that the flexible characteristics of the structure are prominent, which can carry more preprestressed pressure of the base and alleviate the traditional problem of excessive pressure of the base. It has been obviously improved and durable.

The analysis of water content in concrete is of great help to understand this new material. The water in fresh concrete can be divided into bound water, wet water and free water. Water consumed by cement hydration after adding water. This part of water is defined as the combined water in fresh concrete. the combined water can not be replaced by the moisture of the adjacent parts or escaped from the mixture. after the gel material and aggregates, the surface tension of the gel material and aggregates will absorb a certain amount of water to moisten the dry material. This part of water is defined as wetting water. Wet water is adsorbed on the surface of solid materials. The mixture escapes but can be replaced by moisture in adjacent parts; the rest of the water is free water and used as a lubricant in fresh concrete. The slump of concrete depends largely on the amount of free water and its lubricating effect. This part of water has less contact with solid materials and can escape concrete. The density of water in all raw materials is minimal. After escape, it floats to form seepage, which is also called seepage. The detailed structure of the non-woven template lining is shown in figure 1 .

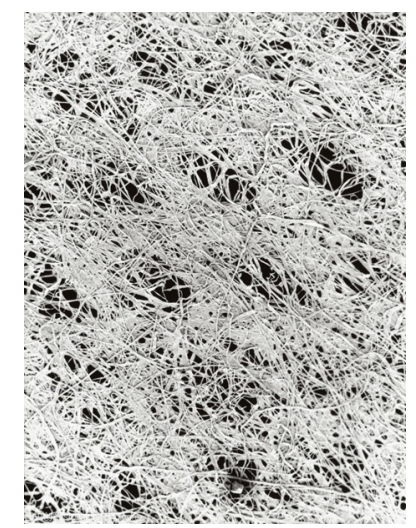

Fig. 1 Details of nonwoven fabric lining

As shown in figure 1, in the detailed structure of the nonwoven template lining, there are pores that can be permeable and breathable, but with its good material, it can also play the effect of heat preservation. It is a very good new material with strong durable and strong bearing capacity.

The water needed to meet the hydration effect of cement accounts for about $20 \% \sim 25 \%$ of the cement dosage, but the water needed to meet the requirements of construction and easiness accounts for about $40 \% \sim 75 \%$ of the total amount of cement materials, and its water-cement ratio is much greater than $25 \%$. After the completion of the pouring process — the segregation of concrete separates aggregate from cement mortar and forms a weak interface connection between aggregate due to the lack of cement slurry bonding. During hardening, volume shrinkage leaves many voids and cracks in concrete. The local accumulation of water forms a large number of macroporous and pore — the results inevitably lead to the decline of concrete impermeability and the durability of concrete capillary. ${ }^{[10]}$

In the concrete construction technology, the process of concrete entry and the vibration of vibrating rod must bring the gas composition in the air. The traditional formwork and concrete contact surface are completely closed. The results also lead to the decrease of concrete impermeability and durability.

After the initial setting of concrete, if the surface layer of the structure is not maintained in time, the surface will crack due to lack of water, the result will also lead to the decrease of the impermeability of concrete, and the durability of concrete will also decrease.

To sum up, under the condition of ensuring the construction and easiness of concrete, the ideal formwork structure should have: the excess moisture and harmful gas in concrete can be discharged before the initial setting of concrete, and after the initial setting of concrete, It can provide moisture for initial maintenance in time. 


\subsection{Analysis of thermal insulation technology}

The requirement of concrete for heat preservation is very high, too hot temperature will affect the hardening of concrete, too low temperature will lead to concrete can not solidify and cracks, water proportion imbalance and so on.During the hardening of concrete, cement releases a lot of hydration heat, and the internal temperature rises continuously, which causes tensile stress on the surface. The decrease of temperature will also cause great tensile stress on the concrete surface. Cracks occur when these tensile stresses exceed the tensile capacity of concrete. The internal humidity of many concrete changes little or slowly, but the surface humidity may change greatly or dramatically. If the curing is not timely, dry and wet, the surface dry shrinkage deformation is constrained by the internal concrete, which often leads to cracks. The technical formula of heat preservation and temperature control is expressed as follows:

$$
P=E \mathrm{r}+\alpha P+\beta P
$$

(Formula 4)

The $\mathrm{P}$ is the final temperature index of heat preservation, the Er value represents the constant temperature value, the normal temperature value under the traditional situation, and the $\alpha \mathrm{P}$ represents the concrete reading of the one-stage heat preservation temperature control . $\beta$ P represents the two-stage temperature control of the specific reading.

The experimental results are shown in Table 2.

Table 2 Test results of thermal insulation test

\begin{tabular}{ccc}
\hline Project & $\begin{array}{c}\text { (c) Traditional } \\
\text { thermal } \\
\text { insulation }\left({ }^{\circ} \mathrm{C}\right)\end{array}$ & $\begin{array}{c}\text { Heat preservation } \\
\text { after improvement } \\
\left({ }^{\circ} \mathrm{C}\right)\end{array}$ \\
\hline $\mathrm{Er}$ & 22 & 22 \\
$\alpha \mathrm{P}$ & 20 & 22 \\
$\beta \mathrm{P}$ & 18 & 24 \\
\hline
\end{tabular}

As can be seen from table 2, Under Er constant temperature of $22^{\circ} \mathrm{C}, \alpha \mathrm{P}$ the first stage of insulation test results, the traditional insulation is $20^{\circ} \mathrm{C}$, Down by two ${ }^{\circ} \mathrm{C}$, $\beta \mathrm{P}$ the second stage of thermal insulation test results, the traditional thermal insulation is $18^{\circ} \mathrm{C}$, A decrease of $4^{\circ} \mathrm{C}$; Improved thermal insulation, With a constant temperature of $\mathrm{Er}{ }^{\circ} \mathrm{C} 22, \alpha \mathrm{P}$ the first phase of the insulation test results, the traditional insulation is $22^{\circ} \mathrm{C}$, Without lowering the temperature, $\beta \mathrm{P}$ the second stage of thermal insulation test results, the traditional thermal insulation is $24^{\circ} \mathrm{C}$, A rise of two ${ }^{\circ} \mathrm{C}$. This shows that the improved material insulation performance is more reliable, It is more helpful to improve the thermal performance of building structure.

The internal temperature of concrete is related to the volume of concrete and the variety and dosage of cement. The larger the volume of concrete, the greater the amount of cement, the higher the hydration heat, the higher the internal temperature, the greater the temperature stress and the greater the possibility of cracks. For mass concrete, the temperature stress is related to its structure size. In a certain size range, the larger the size of concrete structure, the greater the temperature stress, so the greater the risk of cracks. This is the main reason why mass concrete is prone to temperature cracks. It can be seen that the control of temperature stress plays a key role in crack control.

Current measures to control temperature :1) improving aggregate gradation of concrete, Dry hard concrete, Choose medium heat Portland cement or low heat slag Portland cement, Reduce cement usage; 2) using secondary mixing of concrete, It can effectively prevent moisture from gathering at the interface between cement mortar and stone, After hardening, the interface transition layer structure is dense and the adhesion is increased, thereby increasing concrete strength by $10 \%$ or saving cement by $5 \%$, and further reduce hydration heat and cracks; 3) mixed with mixture. Add air entraining agent or plasticizer to reduce cement content in concrete. A large number of experimental studies and engineering practices show that, With a certain amount of fly ash in the concrete, Not only can it replace some cement, And because the fly ash particles are spherical with ball effect, Lubricating, It can improve the fluidity, cohesion and water retention of concrete mixture, For pumping concrete, At the same time, the hydration heat of cement in concrete can be reduced. Add a certain amount of admixture to the concrete which has the function of reducing water, retarding, Improve the fluidity and water retention of concrete mix, Reduce hydration heat, Delay the occurrence time of hydration heat peak; 4) reducing pouring thickness when pouring concrete in hot weather, Use the pouring layer to dissipate heat or lay water pipes in concrete, Cooling through cold water; 5) winter construction, Pay attention to the concrete surface insulation measures, Against the cold, This is especially true for concrete slabs and thin-walled structures.

\subsection{Production techniques for template lining of nonwovens}

Based on the requirements of the concrete surface layer for the formwork lining, the characteristics of the multilayer liner structure and the application environment of the formwork lining, the three-layer structure is adopted in the realization of the non-woven formwork lining technology. The main process routes are shown in figure 2 :

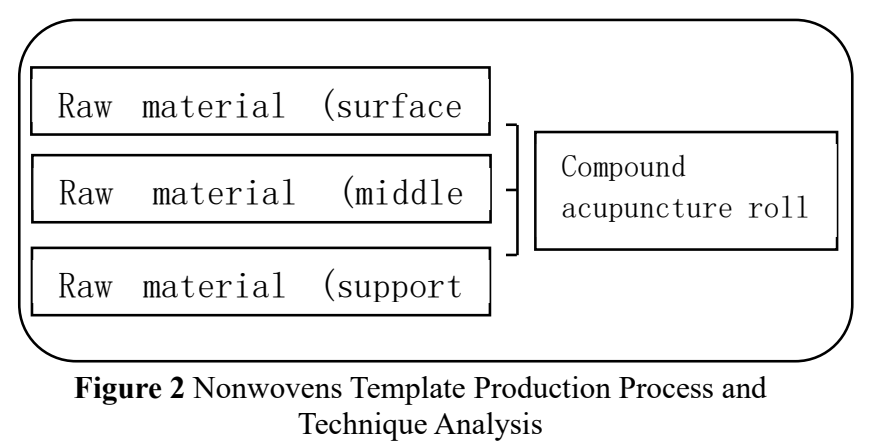

As shown in figure 2, there are three different processes and links in the surface layer, middle layer and support layer of the nonwoven template making process, but the basic workflow is the same, and the later workflow is the same. 
The common polypropylene (PP) fiber is selected in the selection of raw materials, but the PP is nonpolar polymer with poor wetting ability. The contact angle of water to them is large, the surface tension is small, and the wetting ability is poor. In order to make concrete formwork liner have the necessary permeability, hydrophilic treatment is carried out in process design to make it have better permeable effect.

The surface layer of nonwoven template lining is a multi-porous layer, which is formed by 2-3 layers of fiber mesh pre-needle. It is in direct contact with concrete to realize the function of permeable, breathable and preventing the loss of cement particles. During the product structure design, the function of preventing cement particle loss is ensured. The linear density of fiber is 1-1.5 dtex( the smaller the linear density of fiber is, the greater the cohesion between fibers is, and the easier it is to distribute evenly. The porosity decreases and the permeability decreases. In order to facilitate demoulding, the surface layer is required to be smooth, the hairiness is less and short.

The porous layer with large pore size in the middle layer of nonwoven template lining is formed by 3-4 layers of fiber mesh pre-needle. Mainly realize the function of water permeability, air permeability and water retention. Fiber linear density of 3.5-4.5 dtex, increase the porosity between fibers, increase the porosity, increase permeability coefficient, water permeability, permeability it can effectively cast the newly poured concrete surface excess water and air, reduce the surface layer water to cement ratio value.

As the supporting layer, the outer layer of nonwoven template liner has more hairiness, which is formed by 2-3 layers of fiber mesh with linear density of 6-8 dtex. The main implementation and template bonding strength, and play a supporting and fixing role. In order to facilitate the use of adhesive and template good bonding, contact with the template surface hair treatment, in order to achieve better bonding effect.

In the compound acupuncture process, a process is arranged to make the higher denier fiber play the role of reinforcing reinforcement in the layer structure, so that the nonwoven template lining has higher tear resistance. The finishing process should ensure both pore and pore size, smooth and hairiness.

\section{4 bundles}

The surface layer of nonwoven template lining is a multiporous layer, which is formed by 2-3 layers of fiber mesh pre-needle. It is in direct contact with concrete to realize the function of permeable, breathable and preventing the loss of cement particles. During the product structure design, the function of preventing cement particle loss is ensured. The linear density of fiber is 1-1.5 dtex(the smaller the linear density of fiber is, the greater the cohesion between fibers is, and the easier it is to distribute evenly. The porosity decreases and the permeability decreases. In order to facilitate demoulding, the surface layer is required to be smooth, the hairiness is less and short. The porous layer with large pore size in the middle layer of nonwoven template lining is formed by 3-4 layers of fiber mesh pre-needle. Mainly realize the function of water permeability, air permeability and water retention. Fiber linear density of 3.5-4.5 dtex, increase the porosity between fibers, increase the porosity, increase permeability coefficient, water permeability, permeability it can effectively cast the newly poured concrete surface excess water and air, reduce the surface layer water to cement ratio value. As the supporting layer, the outer layer of nonwoven template liner has more hairiness, which is formed by 2-3 layers of fiber mesh with linear density of 6-8 dtex. The main implementation and template bonding strength, and play a supporting and fixing role. In order to facilitate the use of adhesive and template good bonding, contact with the template surface hair treatment, in order to achieve better bonding effect. Nonwovens formwork lining technology is a new technology to improve the durability of building concrete structure by using nonwovens technology. It also takes into account the needs of concrete construction and ease and the need to improve the impermeability of concrete structure surface.

\section{References:}

1. Application of Prefabricated Concrete Sandwich Insulation Wallboard [J].] Reflections Li Xena, Cai Huanqin, Ma Jianlock. Windows and doors. 2017(06)

2. Design Proposal for Thermal Performance Optimization of Prefabricated Concrete Sandwich Insulation Panel Zhu Wenxiang, Xu Jinfeng, Wu Zhimin, Zhang Haiya. Concrete.

3. Design and Application of an Exceeding Limit Sandwich Insulation Wall Building in Shanghai [J].]; and Guo Lianqin. Construction technology development. 2020(12)

4. Building Quality Control [J].] of Prefabricated Concrete Sandwich Insulation Panel Geng Xinlu. Construction. 2020(03)

5. Economic Comparative Analysis and Control [J].] of Prefabricated Sandwich Insulation Exterior Wall Structure Guo Yankun, Ma Yueqiang, Lu Yu Geng. Construction techniques. 2020(17) 